\title{
Researching The Process Of Hydrogen Generating From Water With The Use Of The Silicon Basis Alloys
}

\author{
Mykola Zipunnikov*a, Svetlana Bukhkalo ${ }^{\mathrm{b}}$, Anatolii Kotenko ${ }^{\mathrm{a}}$ \\ ${ }^{a}$ Hydrogen Energetics Department, A.M. Pidhorny Institute of Mechanical Engineering Problems of \\ NASU, 2/10, Pozharsky str., 61046, Kharkiv, Ukraine \\ ${ }^{b}$ National Technical University “Kharkiv Polytechnic Institute”, 2, Kyrpychova str., 61002, \\ Kharkiv, Ukraine \\ zipunnikov_n@ukr.net
}

Keywords: ferrosilicon, ferrosilicon aluminium, hydrogen, the reaction completeness.

There was researched the process of hydrogen generating from water with help of the ferrosilicon aluminium and ferrosilicon alloys with additives of the alkaline earth metals.

There was studied the reaction of the considered alloys interaction under changing the $\mathrm{NaOH}$ solution concentration from $10 \%$ to $13,3 \%$ when the initial temperature range was from $90^{\circ} \mathrm{C}$ to $130^{\circ} \mathrm{C}$. There was determined the necessary content of iron and calcium impurities to increase the gas evolution. The recommendations were formulated as to using the alloys of the silicon and iron with barium impurities for hydrogen generating in the gas generators.

\section{Introduction}

Currently the hydrogen application areas are widening. It is associated with the qualitative changes in the chemical, machine-building, metallurgical and energy industries. For example, hydrogen is used at the autonomous objects, in particular at the meteorological stations and air balloon organizations, where it is generated from water by an ordinary method using the standard FS-75 ferrosilicon alloy (Fe-20-25, Si-74-80, Al$0.6, \mathrm{Cr}-0.5, \mathrm{P}-0.05, \mathrm{~S}-0.03)$ [1-13]. The silicon is the main element that displaces hydrogen from water in presence of sodium hydroxide.

By this moment, thermodynamics, kinetics and heat-mass transfer have been investigated under interaction of a sodium hydroxide solution with the standard aluminium powders and the aluminium activated with indium, gallium and tin. As to the experiments with the silicon alloys, there were researched the FS-75 ferrosilicon and the ferrosilicon aluminium alloys (FSA).

\section{Purposes and research tasking}


The purposes of the research are the following:

- To improve the economically feasible hydrogen generation method using the ferrosilicon alloys with additives of alkaline earth metals and ferrosilicon aluminium;

- To determine the theoretical value of the reaction completeness under interaction of ferrosilicon and ferrosilicon aluminium when the $\mathrm{NaOH}$ concentration is changed from $10 \%$ to $13.3 \%$ at the initial temperature range from $90{ }^{\circ} \mathrm{C}$ to $130{ }^{\circ} \mathrm{C}$; -To formulate the recommendations on application of the considered method for hydrogen generating in the gas generators.

\section{Experimental results and their discussion}

The method of hydrogen generation when using the silicon based alloys is described by the equation [4]

$$
\mathrm{Si}+2 \mathrm{NaOH}+\mathrm{H}_{2} \mathrm{O} \leftrightarrow \mathrm{Na}_{2} \mathrm{SiO}_{3}+2 \mathrm{H}_{2} \uparrow .
$$

According to the stoichiometry, it is necessary to take $80 \mathrm{~g}$ of the sodium hydroxide for every $28 \mathrm{~g}$ of the silicon. But the practice of hydrogen generation, especially in the high pressure gas generators, has shown that the amount of sodium hydroxide can be much less, since the hydrolysis of the sodium silicates is according to the equation $2 \mathrm{Na}_{2} \mathrm{O} \cdot \mathrm{SiO}_{2}+\mathrm{H}_{2} \mathrm{O} \leftrightarrow 2 \mathrm{NaOH}+\mathrm{Na}_{2} \mathrm{O} \cdot 2 \mathrm{SiO}_{2}$.

As a result, the free sodium hydroxide is liberated and sodium silicate is formed with a module of $n=2$. In the technical area of knowledge the sodium silicates are usually called as the soluble glass, and their solutions - as the liquid glass. The main characteristic of the soluble glass is the number $n$, which shows how many the silicon molecules $\mathrm{SiO}_{2}$ is charged per one molecule of the sodium oxide $\mathrm{Na}_{2} \mathrm{O}$. The sodium silicate with $\mathrm{n}=2$ can be further hydrolyzed with forming the silicates with a larger module. The solution of silicates in water can be in general represented by the formula $\mathrm{Na}_{2} \mathrm{O} \cdot \mathrm{nSiO}_{2} \cdot \mathrm{mH}_{2} \mathrm{O}$, where $m$ is the number of those water molecules that are included in to the silicates [14].

The main kinetic studies are carried out in the reactor, which provides isochronous driving the process $\left(\mathrm{V}=1.13 \cdot 10^{-3} \mathrm{~m}^{3}\right)$. As the main hydrogen generating alloys, there were selected (the mass fraction,\%): FS 90 -Fe-4.0, Si-92, Al3.0, Ca-1.0; FS 90 Ba4 - Fe - 5.9, $\mathrm{Si}$ - 88.6, Ba - 4.0, $\mathrm{Ca}-1.5$; FS $75 \mathrm{Ba}$ - Fe - 19.3, $\mathrm{Si}-78.4, \mathrm{Al}-1.3, \mathrm{Ba}$ - 1.0; FSA 4 - Fe - 5.8, Si - 90.4, Al - 3.8; FSA 30 - Fe - 10.3, $\mathrm{Si}$ - 59.9, Al - 29.8; FSA 32 - Fe - 5.5, Si 62.3, $\mathrm{Al}-32.2$.

The results of the main series of the experiments are presented in Tables 1-2 and in Figures 1-3.

The reaction is monitored by increasing the pressure in the reactor. The released gas amount is fixed by the gas meter of GSB-400 type. The degree of conversion $\alpha_{\mathrm{T}}$ is defined as the ratio of the released hydrogen maximum volume and theoretically possible one. 


$$
\alpha_{\mathrm{T}}=V_{r} / V_{T},
$$

where $\mathrm{V}_{\mathrm{r}}$ is the led to the normal conditions amount of hydrogen released during the reaction; $\mathrm{V}_{\mathrm{T}}$ is the volume of hydrogen released under the interaction of $\mathrm{m} \mathrm{kg}$ of a pure element ( $\mathrm{Si}$ or $\mathrm{Al})$ with water. For the alumina compounds $V_{\mathrm{T}}$ is determined by the rule of additivity for the alloy active part.

Table 1. Dependence of the hydrogen evolution speed and the FSA - FS alloys reaction completeness on the sodium hydroxide concentration and the initial temperature $t=$ $90{ }^{\circ} \mathrm{C}$. The alloys disperse composition is $(0.5-1.5) \cdot 10^{-3} \mathrm{~m}$, $m=5 \cdot 10^{-3} \mathrm{\kappa g}$.

\begin{tabular}{|c|c|c|c|c|c|c|}
\hline$\frac{01}{2}$ & 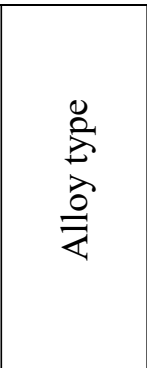 & 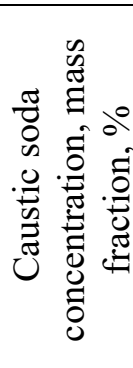 & 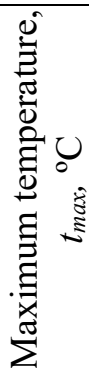 & 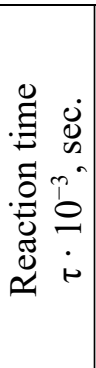 & 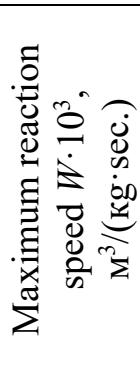 & 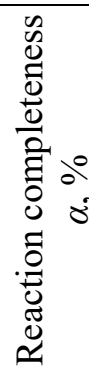 \\
\hline $\begin{array}{l}1 \\
2\end{array}$ & FS 90 & $\begin{array}{c}10 \\
13,3\end{array}$ & $\begin{array}{l}102 \\
104\end{array}$ & $\begin{array}{l}5,7 \\
5,4\end{array}$ & $\begin{array}{c}0,017 \\
0,02\end{array}$ & $\begin{array}{l}46 \\
48\end{array}$ \\
\hline $\begin{array}{l}3 \\
4 \\
\end{array}$ & FS $90 \mathrm{Ba} 4$ & $\begin{array}{c}10 \\
13,3 \\
\end{array}$ & $\begin{array}{l}102 \\
105 \\
\end{array}$ & $\begin{array}{c}2,94 \\
3 \\
\end{array}$ & $\begin{array}{l}0,18 \\
0,12\end{array}$ & $\begin{array}{l}48 \\
50 \\
\end{array}$ \\
\hline $\begin{array}{l}5 \\
6\end{array}$ & FS 75 Bal & $\begin{array}{c}10 \\
13,3\end{array}$ & $\begin{array}{l}105 \\
104 \\
\end{array}$ & $\begin{array}{l}2,4 \\
1,5\end{array}$ & $\begin{array}{c}0,009 \\
0,16\end{array}$ & $\begin{array}{l}45 \\
60\end{array}$ \\
\hline 7 & FSA 4 & 13,3 & 107 & 3,3 & 0,8 & 60 \\
\hline $\begin{array}{l}8 \\
9 \\
\end{array}$ & FSA 30 & $\begin{array}{c}10 \\
13,3 \\
\end{array}$ & $\begin{array}{l}91 \\
94 \\
\end{array}$ & $\begin{array}{c}4,92 \\
4,8 \\
\end{array}$ & $\begin{array}{l}0,42 \\
0,46 \\
\end{array}$ & $\begin{array}{l}28 \\
30 \\
\end{array}$ \\
\hline 10 & FSA 32 & 13,3 & 104 & 3,6 & 0,17 & 54 \\
\hline
\end{tabular}

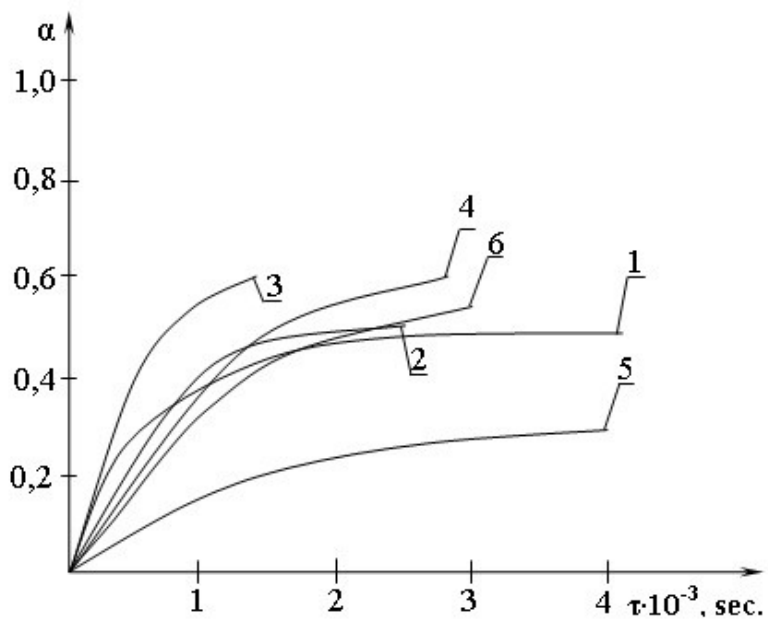

Figure 1. Dependence of the reaction completeness on the time $\tau$ under $13.3 \%$ sodium hydroxide concentration and the initial temperature $t=90{ }^{\circ} \mathrm{C}$ for the alloys 1-FS 90; 2 - FS 90 Ba4; 3- FS 75 Ba1; 4 - FSA 4; 5- FSA 30; 6 - FSA 32.

Table 2. Dependence of the hydrogen evolution speed as well as the FSA and FS alloys reaction completeness on the sodium hydroxide concentration under initial temperature $130^{\circ} \mathrm{C}$. The alloys disperse compositionis $(0.5-1.5) \cdot 10^{-3} \mathrm{~m}$, $m=5 \cdot 10^{-3} \mathrm{\kappa g}$.

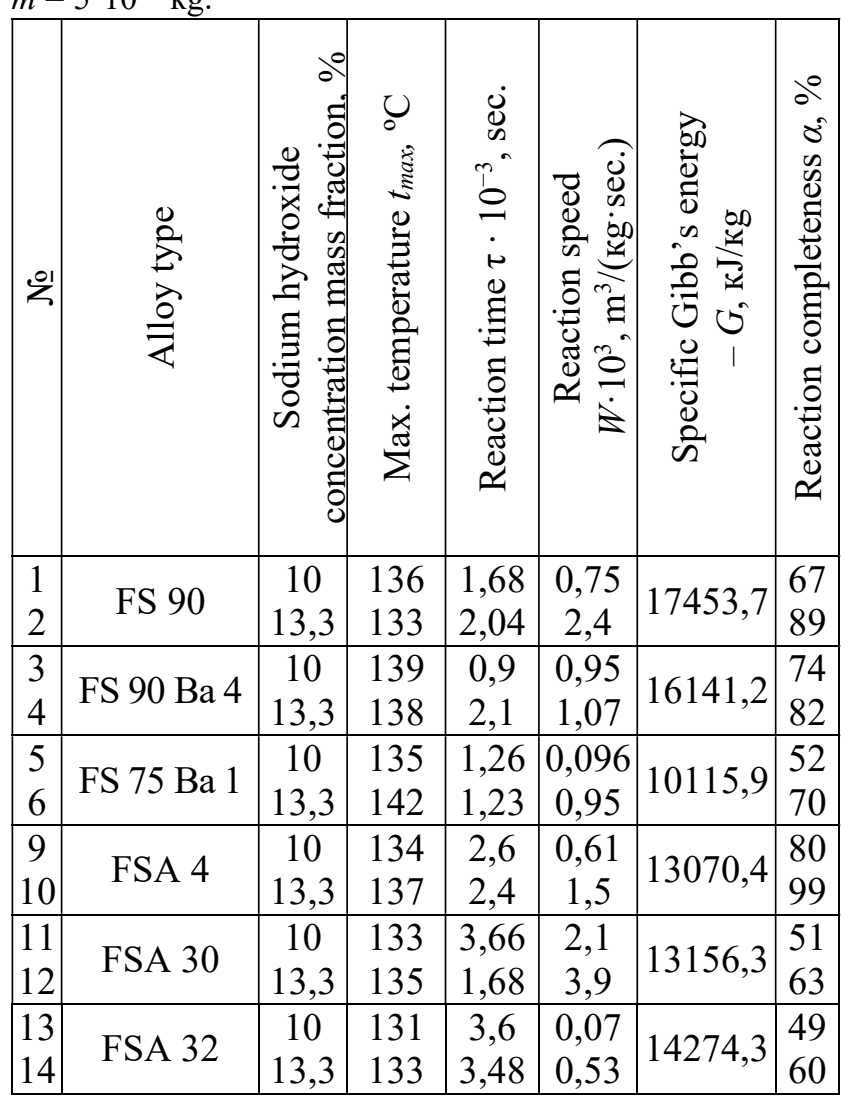




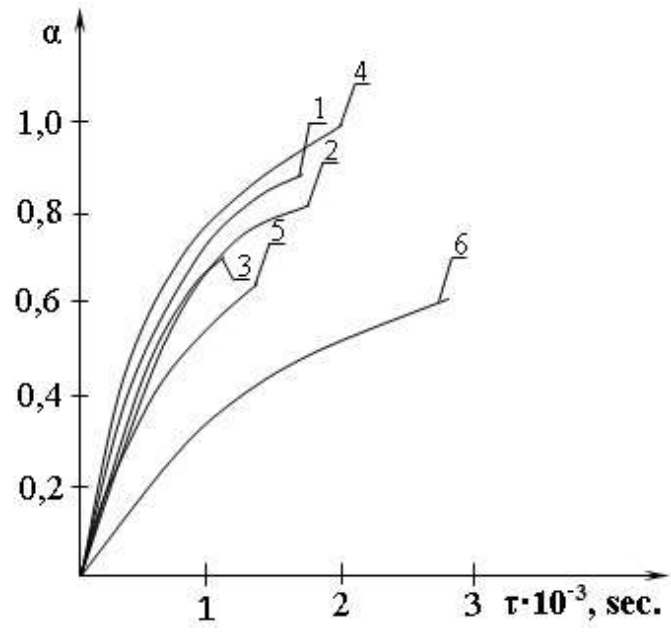

Figure 2. Dependence of the reaction completeness on the time $\tau$ under $13.3 \%$ sodium hydroxide concentration and the initial temperature $t=130{ }^{\circ} \mathrm{C}$ for the alloys: 1 - FS 90; 2 - FS 90 Ba4; 3 - FS 75 Ba1; 4 - FSA 4; 5 - FSA 30; 6 - FSA 32.

Dependence of the reaction completeness on the time $\tau$ under $13.3 \%$ sodium hydroxide concentration and the initial temperature $t=130^{\circ} \mathrm{C}$ for the alloys The diagram of pressure increase in the reactor when the alloys are interacted with a $\mathrm{NaOH}$ aqueous solution is shown in Figure 3.

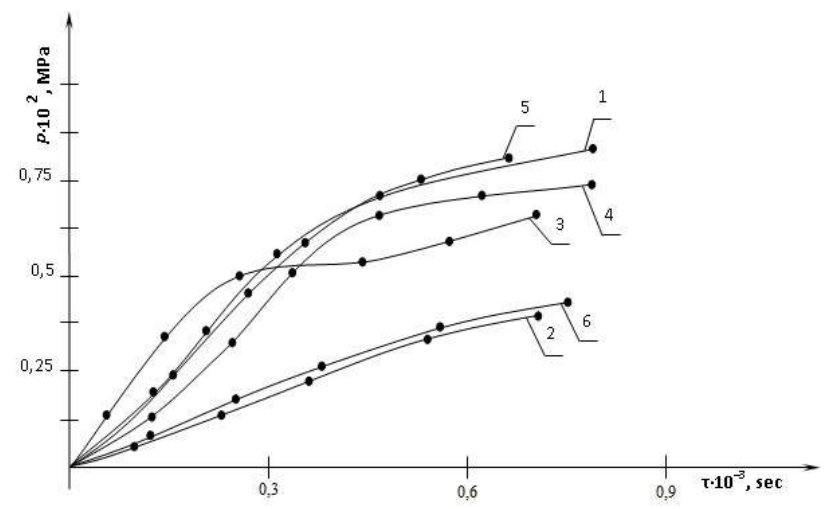

Figure 3. The diagram of pressure change in the reactor $\left(V=1.13 \cdot 10^{-3} \mathrm{~m}^{3}\right)$ when the alloys are interacted with a $\mathrm{NaOH}$ aqueous solution of $13.3 \%, m=1 \cdot 10^{-3} \mathrm{~kg}$ : 1 - FS 90; 2 - FS 90 Ba4; 3 - FS 75 Ba1; 4 - FSA 4; 5 - FSA 30; 6 FSA 32.

The high reaction speeds correspond to the high absolute values of the Gibb's $\left(\Delta G^{o}\right)$ energy at the same temperature - table 2 .

For the reactions taking place under isobarisothermal conditions, the possibility of chemical and phase transformations in a closed system is determined by the equation

$$
\Delta G^{\circ}=\Delta H^{\circ}-T \Delta S,
$$

where $\Delta \mathrm{H}$ is the enthalpy change, $\mathrm{J} / \mathrm{kg} ; \Delta \mathrm{S}-$ the entropy change, entropy, $\mathrm{J} /(\mathrm{kg} \cdot \mathrm{K}) ; \mathrm{T} \quad-$ temperature, $\mathrm{K}$.

The rate of hydrogen evolution is calculated according to the formula

$$
W=\frac{\Delta V}{m \cdot \Delta \tau},
$$

$\mathrm{V}$ - the volume of generated hydrogen, $\mathrm{m}^{3} ; \Delta \tau$ - the time for evolution of this gas volume, seconds; $\mathrm{m}$ is the alloy mass, $\mathrm{kg}$.

The negative values of the Gibb's energy change indicate a high probability of the gas evolution reactions when the FS and FSA alloys are interacted with a $\mathrm{NaOH}$ aqueous solution. The FS 90 and FS 90 Ba4 alloys are characterized with the higher gas evolution speed and reaction completeness, than FSA 30 and FSA 32 alloys, which are made by smelting the pure components (Fig. 2-3, Table 2). The alloy FS 90 has got the maximum evolution speed of $W_{\max }=2.4 \cdot 10^{-}$ ${ }^{3} \mathrm{~m}^{3} / \mathrm{kg} \cdot \mathrm{sec}$. and the reaction completeness of $\alpha=0.89$ in the alloys dispersed composition $(0,5-1,5) \cdot 10^{-3} \mathrm{~m}$ and $13.3 \% \mathrm{NaOH}$. The FS 90 high activities due to presence of the calcium and 
aluminum in its composition that results in increasing the hydrogen evolution speed and reaction completeness (Fig. 2-3, Table 2). At $10 \%$ concentration of the caustic soda, the FS 90 gas evolution speed is $W_{\max }=0.75 \cdot 10^{-3} \mathrm{~m}^{3} / \mathrm{Kg} \cdot \mathrm{sec}$. and $\alpha=0.67$, as well as the FSA 30 alloy gas evolution speed is $W_{\max }=2.1 \cdot 10^{-3} \mathrm{M}^{3} / \mathrm{kg} \cdot \mathrm{sec}$. and $\alpha_{\mathrm{r}}$ $=0.51-$ table 2 . The speed decrease is obviously due to the blurring of the aluminum hydroxide formed on the alloys surfaces.

Under increasing the initial temperature from 90 to $130^{\circ} \mathrm{C}$, the gas evolution speed increases significantly for the alloys with a silicon content of more than $75 \%$ (FS 90, FS 90 Ba4,

FS 75 Ba1, FSA 4) (Fig. 1-2, Tables 1-2).

The results of the experiments with the FS 90 and FS $90 \mathrm{Ba} 4$ alloys containing the iron and calcium show that the rate of their interaction with a sodium hydroxide aqueous solution is higher than the FSA alloys interaction rate - (Fig. 1-2, Tables 1-2). With temperature increasing the calcium, which is the alloys part, rapidly displaces hydrogen from water forming the $\mathrm{Ca}(\mathrm{OH})_{2}$ dihydroxide. The gas evolution is increased only under relatively small additions, namely, iron is of $3-5 \%$ and calcium is of 1 $10 \%$. We have established this regularity and it corresponds to the data of the paper [15].

When the sodium hydroxide concentration is decreased from 13.3 to $10 \%$ at the same temperature, the FS $90 \mathrm{Ba} 4$ alloy reaction completeness is higher than the FS 90 reaction completeness - table 1 . This indicates that the contacting with water barium forms its alkaline environment, which provides the possibility for reducing the sodium hydroxide consumption by $10-15 \%$ and for increasing the amount of generated hydrogen.

The temperature increase from 90 to $130^{\circ} \mathrm{C}$ leads to the $1.5-2$ times reaction completeness increase for the most alloys. At the same time, the reaction speed increases significantly. The main factor that affects the reaction under interaction of the ferrosilicon alloys with the barium additions is the presence of the silicon barium compounds $\left(\mathrm{BaSi}_{2}\right)$ in their structure, which interact with water by the following reactions

$$
\begin{gathered}
\mathrm{BaSi}_{2}+6 \mathrm{H}_{2} \mathrm{O} \leftrightarrow \mathrm{Ba}(\mathrm{OH})_{2}+2 \mathrm{SiO}_{2}+5 \mathrm{H}_{2} \uparrow ; \\
\mathrm{BaSi}_{2}+5 \mathrm{H}_{2} \mathrm{O} \leftrightarrow \mathrm{BaO} \cdot 2 \mathrm{SiO}_{2}+5 \mathrm{H}_{2} \uparrow .
\end{gathered}
$$

With increasing the reaction temperature of more than $130{ }^{\circ} \mathrm{C}$, the silicon barium compounds are destroyed, while the reaction products are freely removed from the gas generator. Therefore, under hydrogen generation in the reactors operating at atmospheric pressure and temperatures up to $100{ }^{\circ} \mathrm{C}$, the presence of alkaline earth metals in the alloys is undesirable. Therefore, under hydrogen generation from water when using the silicon-based alloys with impurities of alkaline earth metals, the reaction products unload process is simplified that greatly 
improves the process of the autonomous hydrogen generators maintenance.

\section{Conclusions:}

[1] Under increasing the initial temperature from 90 to $130^{\circ} \mathrm{C}$, the gas liberating speed increases significantly for alloys with a silicon content of more than 75\% (FS 90, FS 90 Ba4, FS 75 Ba1, FSA 4). The speed decreasing is obviously due to the blurring of aluminum hydroxide formed on the alloys surfaces.

[2] The crystalline FS alloys containing barium and calcium in their composition are the more active than FSA 30 and FSA 32 alloys. Reducing the sodium hydroxide concentration from 13.3 to $10 \%$ for the FS $90 \mathrm{Ba} 4$ and FS $75 \mathrm{Ba} 1$ alloys gives the possibility for increasing their reaction completeness up to $12-15 \%$ compared to the FS and FSA alloys reaction completeness.

[3] The temperature increase from 90 to $130^{\circ} \mathrm{C}$ leads to the 1.5-2 times reaction completeness increase for the most alloys. At the same time, the reaction speed increases significantly. Under hydrogen generation in the reactors operating at atmospheric pressure and temperatures up to $100{ }^{\circ} \mathrm{C}$, the presence of alkaline earth metals in the alloys is undesirable.

[4] Application of the alloys with barium additives in a hydrogen generator gives the possibility for approximately $10-15 \%$ reducing the caustic soda consumption and for reducing the harmful substances emissions into environment. At the same time, the reaction products are freely removed from the gas generator.

\section{References}

[1] Soler L., Macanás J., Muñoz M., Casado J. Aluminium and aluminium alloys assources of hydrogen for fuel cell applications. Journal of Power Sources. 2007, vol. 169, pp. 144-149.

[2] Rodaykan V.V. Calcium, its compounds and alloys. Moscow: Metallurgy. 1967, 188 p.

[3] Troshenkin B.A. Circulation and film evaporators and hydrogen reactors. Kiev: Scientific thought. $1985,174 \mathrm{p}$.

[4] Souza Santos P., Souza Santos H., Toledo S.P. Standard Transition Aluminas: Electron Microscopy Studies. Materials Research. 2000, vol. 3, no. 4, pp. 104-114.

[5] Hord J. Hydrogen safety: An annotated bibliography of regulations, standards and guidelines. Int. J. Hydrogen Energy, Pergamon Press. 1980, 5, pp. 579 584.

[6] Jurmanov V.A., Troshenkin B.A. Automatic facility for generation of hydrogen from water using aluminium/silicic fusion. WMO Techn. Conf. on instrument and method of observ. - Vienna, Austria. 1992, 462, 49 p.

[7] Soler L., Macanás J., Muñoz M., Casado J. Aluminum and aluminum alloys as sources of hydrogen for fuel cell applications. Journal of Power Sources, 2007, vol. 169, pp. 144-149.

[8] Souza Santos P., Souza Santos H., Toledo S.P. Standard Transition Aluminas: Electron Microscopy Studies. MaterialsResearch. 2000, vol. 3, no. 4, pp. 104114.

[9] Neumann Peter, Von Linde Florian. Opportunities for an economical hydrogen supply. // INFORM: Int. NewsFats, OilsandRelat. Mater. 2003, 14 (5), pp. 313-315. 
[10] Dmitriev A.L, Prokhorov N.S., Grishin V.G. Hydrogen generator based on aluminum powder and intermetallic alloys. // Chemical industry. 2006, 3, pp. 134138.

[11] Shevchenko A.A. The use of ELAELs in autonomous power plants characterized by uneven energy supply. Aviation space technology and technology. Aerospace Technic and Technology. Kharkov: Kharkiv Aerospace University "KhAI". 1999, iss. 13, pp. 111-116.

[12] Troshenkin V.B., Zippunikov N.N. State of developments on the study of the process and design of equipment for the production of hydrogen from water using alloys. Vestnik NTU "KhPI". 2008, 12, pp. 51-55. http://repository.kpi.kharkov.ua/bitstream/KhPI$\underline{\text { Press/32789/1/vestnik_KhPI_2008_12_Troshenkin_Sosto }}$ yanie razrabotok.pdf

[13] Zippunikov N.N. The regularities of heat and masstransfer under interaction of silicon-based alloy with water in hydrogen reactors. East-European Journal of Advanced Technologies. 2009, 2/7 (38), 52-55. https://elibrary.ru/item.asp?id $=23127168$

[14] Grigoriev P.N., Matveev M.A. Soluble glass (production, properties and application). Moscow: Promstroizdat. 1956, 246 p.

[15] Povolotsky V.D., Ryabchikov I.V. Improving the metal production quality and production efficiency. 1981, pp. 62-63. 